$10-2013$

\title{
Proposed Performance Standards for the Plank for Inclusion Consideration Into the Navy's Physical Readiness Test
}

David D. Peterson

CedarvilleUniversity, ddpeterson@cedarville.edu

Follow this and additional works at: http://digitalcommons.cedarville.edu/

kinesiology_and_allied_health_publications

Part of the Exercise Science Commons

\section{Recommended Citation}

Peterson, David D., "Proposed Performance Standards for the Plank for Inclusion Consideration Into the Navy's Physical Readiness Test" (2013). Kinesiology and Allied Health Faculty Publications. 53.

http://digitalcommons.cedarville.edu/kinesiology_and_allied_health_publications/53 


\section{Proposed Performance Standards for the Plank for Inclusion Consideration Into the Navy's Physical Readiness Test}

D. D. Peterson, MSC

Aviation Survival Training Center, Naval Air Station, Patuxent River, MD

\section{A B S T R A C T}

SINCE 1982, THE U.S. NAVY HAS
USED THE CURL-UP AS PART OF
ITS SEMIANNUAL PHYSICAL READ-
INESS TEST (PRT) TO ASSESS
CORE MUSCULAR ENDURANCE.
ALTHOUGH NO FORMAL STUDY
HAS BEEN CONDUCTED YET,
THERE IS SPECULATION THAT THE
INCORPORATION OF THE CURL-UP
INTO THE PRT HAS CONTRIBUTED
TO THE NAVY'S LOWER BACK
INJURY RATE. THEREFORE, THERE
HAS BEEN CONSIDERABLE INTER-
EST AS OF LATE TO IDENTIFY A
SAFER (AND MORE OPERATION-
ALLY RELEVANT) ALTERNATIVE TO
THE CURL-UP. THE FOLLOWING
ARTICLE TAKES A FORMAL LOOK
AT THE STANDARD FRONT PLANK
AS A POSSIBLE REPLACEMENT
FOR THE CURL-UP FOR INCORPO-
RATION INTO THE NAVY'S PRT.

\section{INTRODUCTION}

A lthough the Navy currently uses the curl-up to assess core muscular endurance, the test lacks operational relevance and can cause and/or promote low back injuries instead of preventing them (8). Therefore, the standard plank is recommended as a potential replacement for the curl-up as part of the Navy's semiannual Physical Readiness Test (PRT). The benefits of replacing the curl-up with the plank include improved operational relevance, reduction/prevention of back injuries, and a universal performance standard for both genders and all age groups.

As with many field tests currently in practice, there are certain constraints and/or limitations associated with the curl-up. For example, the curl-up places high compressive loads on the low back that can potentially cause or aggravate low back injuries (7). Additionally, the curl-up test has low operational relevance because sailors never perform repetitive torso flexion as a specific job task.

This article will identify more credible means or methods of assessing core muscular endurance for use in the semiannual Navy's PRT.

\section{CURRENT PHYSICAL READINESS TEST}

The U.S. Navy currently uses a 2-minute curl-up, 2-minute push-up, and 1.5-mile run, $450-\mathrm{m} / 500-y d$ swim, 12-minute elliptical, or 12-minute stationary bike test to assess the physical readiness of sailors as part of its semiannual PRT. The curl-up and push-up tests are used to assess core and upper-body muscular endurances, respectively, whereas the run, swim, elliptical, and bike tests are used to assess aerobic capacity. The current PRT does not incorporate a muscular strength test.

All events use age and gender categorized percentiles developed by the Naval Health Research Center from 1997 and 1998 PRT data to score performance. Standards for each performance category are as follows:

Outstanding: Performance above or equal to top 10 percentile.

Excellent: Performance in top 25 percentile but less than Outstanding.

KEY WORDS :

plank; Navy's Physical Readiness

Test; curl-up 
Good: Performance better than/equal to lowest 25 percentile but less than Excellent.

Satisfactory: Performance in bottom 25 percentile but above lowest 10 percentile.

Failure: Performance in lowest 10 percentile.

\section{CURL-UP CONCERNS}

The Navy's curl-up was added to the PRT in 1982 because of its proven validity, reliability, and ease of administration. This is the only test used by all 4 branches of service as part of their semiannual physical fitness assessment and is the standard for core muscular endurance. However, like many other field tests, the curl-up is not without its limitations. Current research depicts several potential concerns associated with prolonged use of spinal flexion exercises-which includes the Navy's curl-up. For example, said exercises impose excessive low back compressive loads that exceed National Institute for Occupational Safety and Health occupational standards (7). "Many athletes with bad backs are prescribed back and abdominal exercises that exceed the tolerance of their compromised tissues. In fact, I believe that many commonly practiced flexion exercises result in so much spinal compression that they will ensure that the athlete becomes a patient! Many institutions still hang on to the idea that speed sit-ups somehow are a test of fitness-this is producing bad backs. Even the traditional slow-speed sit-up imposes approximately 3,300 N (730 lbs) of compression on the spine (the curl-up with feet anchored imposes approximately 2,009 N (452 lbs) of compression on the spine), a criterion injury level set by some governments! It is a poorly designed exercise for many people" (8, p. 95).

Although discredited by some, there is speculation that the lumbar spine has a finite number of bending cycles and exceeding that limit will hasten the onset of intervertebral disk degeneration (3). "Each individual has a loading tolerance which, when exceeded, will cause pain and ultimately tissue damage" (6, p. 36). "The damaging mechanism leading to herniation, or prolapse, is repeated lumbar flexion requiring only very modest concomitant compressive loads. This trauma accumulates with little indication to the future patient. With repeated flexion cycles, the annulus breaches layer by layer with progressive delamination of the layers" (6, p. 35).

In addition, there is little to no operational applicability associated with the curl-up exercise. Core musculature functions differently than limb musculature in that core muscles often cocontract and stabilize the torso, and therefore, core musculature should be trained differently from limb musculature. However, it is a common and widely accepted practice to use repetitive spinal flexion for training the core. "Interestingly, these muscles are rarely used this way because they are more often used to brace while stopping motion. Thus, they more often act as stabilizers than flexors" (6, p. 33). Robertson and Trent (10) found that the majority of Navy's shipboard tasks (roughly 84\%) can be categorized into 3 basic movement patterns: lifting, carrying, and pulling-all of which require a stable core to perform. However, when the spine is flexed, the body's ability to generate power and perform such movements is significantly impaired (6).

Several studies have shown that bentknee sit-ups do not strongly challenge the abdominal musculature, rather the hip flexors, and are not recommended for individuals with chronic low back problems $(1,4)$. Bent-knee sit-ups with feet unsupported have higher myoelectric activity of the rectus abdominis and external oblique musculature (4). Conversely, bent-knee sit-ups with feet supported (as with the Navy's curl-up) are associated with significantly less core muscular and higher hip flexor myoelectric activity (4).

Although not a proponent of excluding spinal flexion exercises altogether, Contreras et al. (3) make the following recommendations before incorporating said exercises into a core conditioning program: (a) Do not exceed 60 repetitions of spinal flexion per training session; (b) Allow a minimum of 48 up to 72 hours of rest between training sessions to allow for adequate recovery and tissue repair; (c) Use spinal flexion exercises when the training goal is improved core muscular strength and/ or hypertrophy (with the addition of external resistance as required to elicit the overload response) not muscular endurance; (d) Use static, neutral posture exercises held for extended periods if the training goal is core muscular endurance; (e) Spinal flexion exercises should be performed at a tempo of approximately 2 seconds per repetition (faster repetition tempos could subject the lumbar spine to high compression loads thus increasing the potential for injury); and (f) Wait a minimum of 2 hours after waking to perform spinal flexion exercises-to account for swelling of the disks from osmotic superhydration that occurs with bed rest $(3,6)$.

Ironically, many of the recommendations of Contreras et al. (3) add legitimacy to the claim that the curl-up may not be well suited for the PRT. For example, Contreras et al. (3) recommend that the number of spinal flexions performed be limited to 60 repetitions or less per session. However, the majority of age and gender categories used to grade curl-up performance for the PRT require the member to perform more than 60 repetitions to score "Excellent" or better. Additionally, Contreras et al. (3) recommend that spinal flexion exercises should be used for improving abdominal muscular strength and/or hypertrophy. The rationale for incorporating the curl-up into the PRT was to assess core muscular endurance-not strength or hypertrophy. Additional research also reported that trunk flexion exercises without additional resistance provide minimal stress to the abdominal musculature $(1,4,5)$. Finally, Contreras et al. (3) recommend that static, neutral posture exercises should be used to assess core muscular endurance. Additional research also supports that isometric trunk stabilization exercises have several favorable characteristics. 
For example, they are easy to perform, require little to no equipment to execute, and rarely result in postexercise muscle soreness (1).

Current research from Childs et al. (2) also supports this recommendation. Childs et al. (2) conducted a study evaluating musculoskeletal injury rates of soldiers enrolled in the U.S. Army Combat Medic course by comparing 2 different core muscular endurance training protocols. They compared one that incorporated traditional sit-up training with one that used core stabilization exercises (including the plank). Of the 1,141 soldiers who participated, 511 (or 44.8\%) experienced musculoskeletal injuries during training. Although there was no statistical difference in the percentage of soldiers experiencing musculoskeletal injuries between groups, there was a statistical difference in the number of work restriction days between groups for soldiers reporting a low back injury. Specifically, the average number of days of work restriction for soldiers incorporating traditional sit-up training was 8.3 days $(\mathrm{SD}=14.5)$, whereas 4.2 days $(\mathrm{SD}=8.0)$ for soldiers incorporating core stabilization exercises. Childs et al. (2) argue that one possible explanation for this finding is that core stabilization exercises provide a certain level of protection against the onset of low back injuries (2).

Based on these and other such findings/recommendations, the Navy has long considered replacing the curl-up with a safer and more operationally relevant exercise. In fact, in 2006, the Deputy Chief of Naval Operations directed a comprehensive assessment of the Navy's Physical Readiness Program (PRP). One of the recommendations from the assessment was to determine the feasibility of replacing the curl-up with either the bridge or the plank exercise.

\section{PLANK RESEARCH}

Although more research is needed to establish industry standards for the plank, a 2010 study conducted by McGill et al. provides the first known data set for plank scores categorized by age and gender. In the study, McGill et al. calculated average plank times for Canadian firefighters and college students. Plank data for the firefighters were collected and compared over a 3-year period (i.e., 2006-2008). In $2006(n=401)$, the average plank time was 118 (1:58) seconds. In 2007 $(n=287)$ and $2008(n=390)$, the average plank times were 129 (2:09) and 153 (2:33) seconds, respectively. A comprehensive listing of the average plank times for Canadian firefighters broken down by age is provided in Table 1.

Of the 181 university students who participated (99 women and 82 men), the average plank time was 183 (3:03) seconds for men and 106 (1:46) seconds for women. In addition, the data were broken down further into participants with no back problems, history of disabling back problems, and history of disabling shoulder problems. Interestingly, there was no statistical difference in plank times based on a history of back or shoulder problems (9). This is an important finding because numerous sailors currently cannot perform pushups because of shoulder constraints but are able to perform the curl-up.

\section{PHYSICAL READINESS TEST BETA TEST}

Additionally, in 2011, the Navy's PRP office conducted a PRT beta test that evaluated 9 different modalities for possible inclusion into the Navy's PRT (11). The purpose of the beta test was to evaluate the validity, objectivity, reliability, operational relevance, and possible redundancy of different field tests currently used and recommended by the industry. One of the exercises evaluated was the single-leg plank. Of all the core muscular endurance tests available, the plank test was chosen based on its lower risk of injury and higher operational relevance.

This single-leg plank variant was selected over the standard front plank because it added a much needed balance component to the PRT. In addition, the single-leg variant would be more difficult to execute for long durations, thus reducing the time required

\begin{tabular}{|c|c|c|c|c|}
\hline \multicolumn{5}{|c|}{$\begin{array}{l}\text { Table } 1 \\
\text { Average plank time for Canadian firefighters }\end{array}$} \\
\hline \multicolumn{5}{|l|}{2006 data } \\
\hline Age group (y) & $20 \mathrm{~s}$ & $30 \mathrm{~s}$ & $40 \mathrm{~s}$ & $50 \mathrm{~s}$ \\
\hline$N$ & 53 & 142 & 103 & 98 \\
\hline Males & 1:55 & 1:53 & 2:04 & 1:51 \\
\hline Females $(n=5)$ & \multicolumn{2}{|c|}{ Average age: 35 y } & \multicolumn{2}{|c|}{$\begin{array}{l}\text { Average plank time: } \\
1: 32\end{array}$} \\
\hline \multicolumn{5}{|l|}{2007 data } \\
\hline$N$ & 38 & 114 & 62 & 66 \\
\hline Males & $2: 12$ & $2: 09$ & $2: 20$ & 1:59 \\
\hline Females $(n=7)$ & \multicolumn{2}{|c|}{ Average age: 33 y } & \multicolumn{2}{|c|}{$\begin{array}{l}\text { Average plank time: } \\
\text { 1:54 }\end{array}$} \\
\hline \multicolumn{5}{|l|}{2008 data } \\
\hline$N$ & 89 & 156 & 76 & 59 \\
\hline Males & $2: 18$ & $2: 23$ & $2: 35$ & $2: 23$ \\
\hline Females $(n=10)$ & \multicolumn{2}{|c|}{ Average age: 32 y } & \multicolumn{2}{|c|}{$\begin{array}{l}\text { Average plank time: } \\
\text { 2:25 }\end{array}$} \\
\hline
\end{tabular}


to facilitate the test. Originally, the intent was to evaluate the single-leg plank with the dominant leg (which was determined by asking the test subject which leg they would use to kick a ball) on the ground with the nondominant leg extended and held parallel to the ground. However, this version primarily stressed the anterior muscles of the dominant leg (i.e., quadriceps femoris, sartorius, and iliopsoas complex) and not the core musculature (i.e., rectus abdominis, obliques, erector spinae, transverse abdominis, and quadrates lumborum). Hall et al. (4) reported that exercises that specifically target and develop the iliopsoas complex tend to cause lumbar lordosis (anterior curvature of the lower portion of the spinal column), which can lead to moderate to severe low back pain. Therefore, a modified version of the single-leg plank was used and evaluated. In this variant, the subject rested their nondominant ankle on top of their dominant ankle (Figure 1).

The subjects were instructed to maintain a straight line through the shoulders, hips, knees, and dominant-leg ankle. Only the outer palms, forearms, and ball of the foot of the dominant leg were allowed to be in contact with the ground. The test was terminated if the subject contacted the ground with any body part other than the palms, forearms, and ball of the foot of the dominant-leg foot or failed to maintain a straight line through the shoulders, hip, knees, and dominantleg ankle after one verbal warning.

Of the 178 total PRT beta test participants, only 163 (125 men and 38

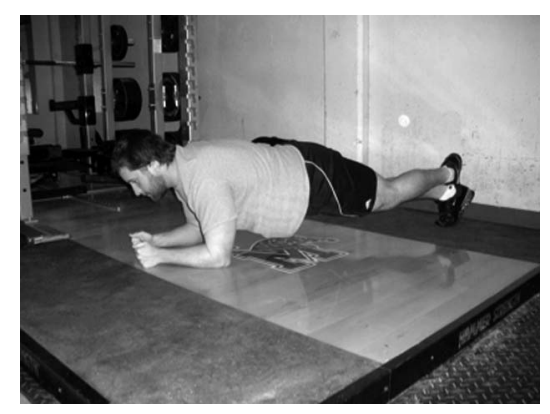

Figure 1. Single-leg plank. Photo taken from Whitehead et al. (11). women) completed both test sessions involving the plank. All participants were active duty military (primarily U.S. Navy) stationed aboard Naval Support Activity Mid-South in Millington, TN. The official testing protocol consisted of three 1-hour sessions conducted in duplicate for a total of 6 training sessions (i.e., session 4 was a duplicate of session 1 , session 5 was a duplicate of session 2, and session 6 was a duplicate of session 3). Only 3 of the 9 modalities were tested during each test session. Because of the limited number of test staff and work commitments of the subjects, only 2 sessions were conducted each week (either Monday/ Thursday or Tuesday/Friday). This equated to 10 days being afforded between like testing sessions.

As with any program designed to improve physical fitness and encourage regular exercise participation, proposed standards should be set at a level that requires frequent conditioning to perform well but not too high to be unobtainable. Through personal interaction and an online postparticipation survey, it was determined that most PRT beta test subjects had never performed a max effort time plank before the beta test. This may explain the relatively poor reliability associated with the plank (percent coefficient of variation $=21.3$ ). Despite its poor reliability, it could be speculated that with additional training and/or addition of a third testing session, timed plank scores would improve and be more consistent over time. Using the data collected from the PRT beta test and percentile data from the 2010 McGill study, proposed percentiles for the plank were developed and are provided in Table 2. Although the single-leg variant was evaluated during the PRT beta test, the standard front plank is being proposed for implementation. This decision was based on the fact that the standard plank is more commonly used and promoted by the industry and possesses easier testing criteria than the single-leg variant.

Because the curl-up test currently has the same standards for both genders within the same age category, one standard was developed for both genders for

\begin{tabular}{|l|c|}
\hline \multicolumn{2}{|c|}{$\begin{array}{c}\text { Table } 2 \\
\text { Proposed percentile norms for } \\
\text { plank (male/female) }\end{array}$} \\
\hline Age $(\mathrm{y})$ & 17 to $65+$ \\
\hline $90 \%$ & $4: 00$ \\
\hline $75 \%$ & $3: 30$ \\
\hline $50 \%$ & $3: 00$ \\
\hline $25 \%$ & $2: 30$ \\
\hline $10 \%$ & $2: 00$ \\
\hline
\end{tabular}

the plank. In addition to gender, the same standard is also being proposed for all age categories. Although current curl-up standards decrease with subsequent age groups, this trend is not supported by the current research evaluating the plank-to include the PRT beta test. In fact, the current world record for the plank is 1:20:05.01 set by a 54-year-old former Marine and Drug Enforcement Administration officer (http://www.thepostgame.com/blog/ healthy-living/201112/george-hoodplanking-world-record, December 09, 2011). The previous world record was set by a 71-year-old woman with a time of 36:58 (retrieved from http:// www.prnewswire.com/news-releases/ 71-year-old-anytime-fitness-memberbreaks-the-guinness-world-record-forholding-plank-position-130740498.html, October 14, 2011). With this in mind, a minimum score of 2:00 and maximum score of 4:00 are being proposed for the plank-which, based on available data, does not seem to be unachievable for most sailors.

\section{CONCLUSIONS}

Since 1982, the Navy has been using the curl-up as a means of assessing core muscular endurance as part of its semiannual PRT. However, current research has shown that repetitive spinal flexion exercises, to include curl-ups, are better suited for muscular strength or size and not recommended for improving core endurance. Additionally, said exercises can actually lead to or cause low back injuries for some individuals. Instead, many researchers are now recommending replacing repetitive spinal flexion exercises 
with isometric trunk stabilization exercises for the purpose of core endurance testing. One example of a common isometric trunk stabilization exercise is the standard plank. The plank is an easy test to administer, operationally applicable, and may actually reduce the likelihood for and occurrences of low back injuries if trained regularly. The plank is a more credible means of assessing core muscular endurance for use in the semiannual Navy's PRT and should be seriously considered as a viable alternative to the curl-up.

Conflicts of Interest and Source of Funding: The author reports no conflicts of interest and no source of funding.

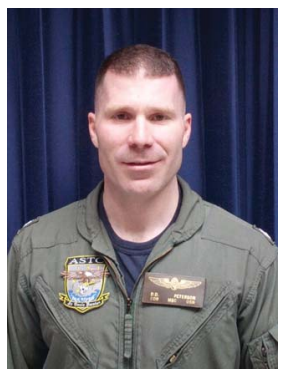

D. D. Peterson is the Director, Aviation Survival Training Center, Patuxent River aboard the Naval Air Station, Patuxent River, Maryland.

\section{REFERENCES}

1. Chen L, Bih L, Ho C, Huang M, Chen C, and Wei T. Endurance times for trunkstabilization exercises in healthy women: Comparing 3 kinds of trunk-flexor exercises. Sport Rehabil 12: 199-207, 2003.

2. Childs JD, Teyhan DS, Casey PR, McCoy-Singh KA, Feldtmann AW, Wright AC, and George SZ. Effects of traditional sit-up training versus core stabilization exercises on short-term musculoskeletal injuries in US Army soldiers: A cluster randomized trial. Phys Ther 90: 1-9, 2010.

3. Contreras B and Schoenfeld B. To crunch or not to crunch: An evidence-based examination of spinal flexion exercises, their potential risks, and their applicability to program design. Strength Cond J 33: 8-18, 2003.

4. Hall SJ, Lee J, and Wood TM. Abdominal and low back muscle involvement during eight situp variations. In: Biomechanics in sports VI: Proceedings of the sixth international symposium on biomechanics in sports. Kreighbaum E and McNeil A, eds. Bozeman, MT: International Society of Biomechanics in Sports, 1990. pp. 399-406.

5. Knudson D and Johnston D. Abdominal muscle activation in two trunk-curl tests. In: Biomechanics in Sports XV: Proceedings of the 15th International Symposium on Biomechanics in Sports. Wilkerson J,
Ludwig K, and Zimmerman W, eds. Denton, TX: Texas Woman's University, 1997. pp. 205-210.

6. McGill S. Core training: Evidence translating to better performance and injury prevention. Strength Cond J 32: 33-46, 2010.

7. McGill S, ed. Low Back Disorders (3rd ed). Champagne, IL: Human Kinetics, 2007.

8. McGill S, ed. Ultimate Back Fitness and Performance (3rd ed). Champagne, IL: Human Kinetics, 2006.

9. McGill S, Belore M, Crosby I, and Russell C. Clinical tools to quantify torso flexion endurance: Normative data from student and firefighter populations. Occup Ergon 9: 55-61, 2010.

10. Robertson DW and Trent TT. Documentation of Muscularly Demanding Job Tasks and Validation of an Occupational Strength Test Battery (STB). San Diego, CA: Naval Personnel Research and Development Center, 1985. Report No. 86-1. Available at: http://www. dtic.mil/cgi-bin/GetTRDoc? $\mathrm{AD}=\mathrm{ADA} 162781$.

11. Whitehead $P$, Schilling B, Peterson D, and Weiss L. Possible new modalities for the Navy Physical Readiness Test. Mil Med 177: 1417-1425, 2012. 